\title{
Rumors of the death of consumer genomics are greatly exaggerated
}

\author{
Razib Khan ${ }^{1}$ and David Mittelman ${ }^{2,3^{*}}$
}

The idea of computation is not new. Gottfried Leibniz in the 17th century had already outlined its basic elements in a formal sense [1], though one could argue that various mechanical calculating devices in Classical Antiquity and in Imperial China prefigured the difference engines of later ages [2]. By the mid-20th century science fiction writers were imagining a few, perhaps even only one, mega computer driving human civilization into the future [3]. Obviously they were wrong. In the first decades of the 21st century computation has proliferated and dispersed; becoming ubiquitous, seamless, almost beneath notice. Rather than exciting exotica, computation is the banal undergirding of modern post-industrial civilization. Devices that in the past would be properly labeled powerful computers are today termed 'phones', 'cars' or 'espresso machines'. We have transitioned from an abstraction of rarified reflection to a plethora of devices geared toward unthinking consumption.

This is the trajectory one might project for what we now term direct to consumer (DTC) or beyond the clinic genomics [4], the ancestor of what is likely to become a ubiquitous form of information technology in the coming decades. If Gregor Mendel was the Leibniz of genomics, we are in the Apple I era, as hobbyists jockey with firms that harbor dreams of massive market share. There is no telling who will be the Microsoft or Apple of this industry, but that is partly because we do not have the equivalent of the VisiCalc yet. The Apple II has not arrived, let alone the Macintosh.

While the sequencing hardware behind the technological revolution is transitioning from the analog of corporate mainframes to desktop-ready devices, the productivity suites of consumer genomics have yet to be fully conceived, let alone implemented. So what applications will drive the industry in the next few years? Front and center in terms of candidates for the next

\footnotetext{
* Correspondence: david.mittelman@vt.edu

${ }^{2}$ Virginia Bioinformatics Institute, Virginia Tech, Blacksburg, VA 24060, USA

${ }^{3}$ Department of Biological Sciences, Virginia Tech, Blacksburg, VA 24060, USA Full list of author information is available at the end of the article
}

'killer app' is the relatively mature market for genetic genealogy. More broadly, genealogy is a maturing sector with billions in revenue and nearly 100 million serious enthusiasts [5]. Rather than creating a demand de novo, genetic genealogy serves to extend the reach and power of those with deep questions as to their ancestry. The appeal of this sector is unsurprising. Cultures as distinctive and varied as the Jews and Chinese are preoccupied with issues of descent. One could argue that a genealogical mindset is a human universal playing to our inner desire to understand ourselves, our origins and our purpose. The tools of modern genomics add depth and insight to answers that most humans crave in their bones. Inclusive of the older genomic techniques, such as microsatellite markers, consumers of genetic genealogy likely number into the millions, with the richer offerings of firms such as Family Tree DNA and 23andMe approaching the order of one million customers next year [6].

We are all products of a past that is sketched out in the broadest sense by phylogenetics. Our pedigrees expand rapidly and then coalesce back together again, as the same individuals show up over and over. This is what evolutionary genomics is telling us [7], but our basic human intuitions often fail to grasp the multigenerational story, which goes beyond great-grandparents, and into the deepest mists of our species' past. DTC genomics in the domain of genetic genealogy can bridge the chasm between the abstruse inferences of population and phylogenetics, and the lived and familiar reality of human familial warmth. But it can only do so by reducing abstract scientific theory into a more human shape, relatable, palatable and compelling. It is trite to assert that 'we are all one big family', but what genomics can do is make this truth concrete, and add some scientific heft behind sentiment. The industry needs to refine and perfect the middle layer between the science and the consumer, to the point where the technical guts of the operating system become as encapsulated, mysterious and ubiquitous as the magic of an iPhone. 
As analysis of ancestry and genealogy saturate over the next decade, it seems likely that a natural segue will be made to medical genomics, as massive sample sizes can finally be leveraged into fine-grained prediction. Genetic genealogy is an applied enterprise of phylogenetics, but adding phenotypic information to the rich implicit pedigrees may finally allow for both true and surprising outcomes in regards to health risk prediction and the general interpretation of genome variants. Eventually the personal information ecology in which we are embedded will be rich, tagged and amenable to being synthesized and reduced down to actionable units. Genetic genealogy complements written records, but its power is such that it can yield information as a standalone tool. Not so when it comes to medical and assorted trait predictions. Most genetic traits of interest are complex, with multiple, sometimes obscure, lines of causality. Modern studies that use hundreds of individuals are notoriously underpowered, and are rapidly being superseded by pooled data sets of hundreds of thousands. Yet this is nothing compared to what will no doubt be the norm in the next decade, as diverse strands of information continuously thread together, and generate a perpetual stream of novel insightful predictions. Imagine that biomarkers are constantly recording your feedback to a particular diet or activity, and this information is intersected with millions with varying levels of genetic relatedness and lifestyle. The computational requirements are immense, but the past few decades have shown us that we can always be surprised how far Moore's Law can take us.

Of course such a scenario above begs the question whether people would be comfortable in a semipermeable soup of information floating in the future cloud. But fortunately, or unfortunately, some of the most powerful and innovative firms today are making Scott McNealy's prediction of a post-privacy future come alive. In the simplest of terms, expectation of privacy evolves with technology. In particular, both Google and Facebook are pushing the public toward the direction of transparency in terms of personal data. For obvious reasons there is sensitivity in regards to medical information in the United States, but with universal coverage some of the concerns are likely to be obviated, while the body politic will also have an incentive to allow for greater information exchange to be leveraged into informing citizens as to the optimal path for a healthier lifestyle [8].

Like the thin edge of the wedge, DTC genomics over the next decade will be defined by first movers who are passionate. Some will be enthusiasts for genealogy, others for experimental bio-hacking, and many for selfimprovement through total self-knowledge. These hobbyists will drive a market segment that caters to their needs by transforming the digital information in their genomes into actionable representations and projections. But once the DTC genomics industry matures it will likely be swallowed in toto by the emerging total information ecology. This is not just likely, but inevitable, because though your genes do not determine who you are, you cannot understand who you are without your genes. It may be tired to declare that the information must be free', but in a deep and fundamental sense emergence of 'big data' and personalization are validating that prediction. And yet just because information flows freely does not imply that it cannot be monetized; both Google and Facebook illustrate that. In the next decade one will see firms that make these companies seem like niche players, as they develop and deploy information utilities that are going to be similar to helper artificial intelligence. This is a future where basic day-to-day decisions will be offloaded to these automated systems, which will receive as inputs both environmental and hereditary variables. Where does that leave humans? Our lot will be to enjoy the good life, reflecting upon the deeper and more important things that are not so reducible by data analysis engines. In contrast to the idea of a post-human future, the information ecology of the next few decades, driven in part by personal genomics, will be even more human as the banal and impersonal decisions that define modern life are taken over by automatons.

\section{Abbreviation}

DTC: Direct to consumer.

\section{Competing interests}

DM is a partner and equity holder in Gene by Gene Ltd, which offers direct to consumer genetic testing.

\section{Author details}

${ }^{1}$ Department of Population Health and Reproduction, School of Veterinary Medicine, UC Davis, Davis, CA 95616, USA. ²Virginia Bioinformatics Institute, Virginia Tech, Blacksburg, VA 24060, USA. ${ }^{3}$ Department of Biological Sciences, Virginia Tech, Blacksburg, VA 24060, USA.

\section{Published: 26 November 2013}

\section{References}

1. Davis M: The Universal Computer: The Road from Leibniz to Turing. 1st edition. New York: Norton; 2000.

2. Koetsier T: On the prehistory of programmable machines: musical automata, looms, calculators. Mechanism and Machine Theory 2001, 36:589-603.

3. Asimov I: The Best Science Fiction of Isaac Asimov. 1st edition. Garden City, NY: Doubleday; 1986

4. Prainsack B, Vayena E: Beyond the clinic: 'direct-to-consumer' genomic profiling services and pharmacogenomics. Pharmacogenomics 2013, 14:403-412.

5. BloombergBusinessweek. Ancestry.com's Genealogical Juggernaut. [http://www.businessweek.com/articles/2012-09-20/ancestry-dot-comsgenealogical-juggernaut]

6. genomeweb: Director of NatGeo Genographic Project Claims Consumer Genomics Has Become 'Mainstream'. [http://www.genomeweb.com/ 
arrays/director-natgeo-genographic-project-claims-consumer-genomics-hasbecome-mainstre]

7. Ralph P, Coop G: The geography of recent genetic ancestry across Europe. PLOS Biol 2013, 11:e1001555.

8. Sanderson SC: Genome sequencing for healthy individuals. Trends Genet 2013, 29:556-558

doi:10.1186/gb4141

Cite this article as: Khan and Mittelman: Rumors of the death of consumer genomics are greatly exaggerated. Genome Biology 2013 14:139. 